\title{
Correction to: Solidification of hydatid cyst fluid with an injectable chitosan/carboxymethylcellulose/ $\beta$-glycerophosphate hydrogel for effective control of spillage during aspiration of hydatid cysts
}

\author{
Mostafa D. A. Azadi ${ }^{1}$ Shadi Hassanajili ${ }^{1} \cdot$ Khalil Zarrabi $^{2} \cdot$ Bahador Sarkari $^{3}$
}

Published online: 7 April 2018

(c) The Author(s) 2018

\section{Correction to: Progress in Biomaterials (2018) 7: 35-54 https://doi.org/10.1007/s40204-018-0082-5}

The original version of this article unfortunately contained a mistake: the spelling of the Shadi Hassanajili's name was incorrect. The corrected name is given above.
Open Access This article is distributed under the terms of the Creative Commons Attribution License which permits any use, distribution, and reproduction in any medium, provided the original author(s) and the source are credited.

The original article can be found online at https://doi.org/10.1007/ s40204-018-0082-5.

Shadi Hassanajili

ajili@shirazu.ac.ir

1 Department of Chemical Engineering, School of Chemical and Petroleum Engineering, Shiraz University, Shiraz, Iran

2 Department of Cardiovascular Surgery, School of Medicine, Shiraz University of Medical Sciences, Shiraz, Iran

3 Department of Parasitology and Mycology, School of Medicine, Shiraz University of Medical Sciences, Shiraz, Iran 